\title{
EFEKTIFITAS ACUYOGA TERHADAP KELUHAN INSOMNIA PADA IBU HAMIL TRIMESTER III DI MASYARAKAT AGRICULTURE TRADITIONAL DI WILAYAH KERJA PUSKESMAS NGANCAR KABUPATEN KEDIRI (The Effectiveness of Acuyoga to the Insomnia Complaints of Pregnant Women in Trimester III in Agriculture Traditional Community in Puskesmas Ngancar Kediri)
}

\author{
Nevy Norma Renityas, Levi Tina Sari, Wahyu Wibisono \\ Program Studi D3 Kebidanan, STIKes Patria Husada Blitar \\ email: tinasari.levi@gmail.com
}

\begin{abstract}
Pregnant mother in the 3rd trimester usually experience sleep disorder caused by discomfort of pain on waist due to the enlargement of uterus to the anterior position. The decline of sleep duration of pregnant mother can also make their condition and concentration decreased, experience fatigue, body feels stiff, mood swing, and tend to be emotional. This condition makes the pregnancy becomes more severe than before (Bambang BR, 2004). Therefore, acuyoga technique is applied in order toreduce insomnia. Acuyoga consists of breathing exercises, meditation, relaxation, and using meridian points in the body to cope with stress and back pain that can cause insomnia in pregnant women. The purpose of this study was to determine the effectiveness of acuyoga techniques to insomnia complaints of 3rd trimester of pregnant women in traditional agricultural communities. The research method used pretest-posttest design with consecutive sampling technique and the number of samples was 40 mothers divided into 4 groups, each group was given treatment 4times in 2 weeks. The measuring tool used the questionnaire and the ISI scale then analyzed by paired sample t-test. The results of the study showed there were an effect of acuyoga technique to insomnia in pregnant women with $t$ count $=13.397$ with ttable $=0.021$. It was expected that acuyoga technique could be one of the techniques to reduce insomnia in pregnant women since it could relax the muscles in the body so that pregnant women felt comfortable.
\end{abstract}

Keywords: acuyoga, insomnia, trimester 3 pregnant women

\begin{abstract}
Abstrak: Ibu hamil trimester 3 mengalami gangguan pola tidur hal ini desebabkan karena ketidaknyamanan rasa nyeri pada pinggang akibat dari pembesaran uterus ke posisi anterior. Penurunan durasi tidur pada ibu hamil dapat membuat kondisi ibu hamil menurun, konsentrasi berkurang, mudah lelah, badan terasa pegal, tidak mood bekerja, dan cenderung emosional.Hal ini dapat membuat beban kehamilan menjadi semakin berat (Bambang BR, 2004).Oleh karena itu, di terapi dengan teknik acuyoga yang diharapkan dapat menurunkan insomnia. Acuyoga terdiri dari latihan pernafasan, meditasi, relaksasi dan menggunakan titik meridian dalam tubuh untuk mengatasi stress dan nyeri punggung yang bisa menyebabkan insomnia pada ibu hamil.tujuan penelitian ini adalah untuk mengetahui efektifitas tehnik acuyoga terhadap keluhan insomnia pada ibu hamil trimester 3 di masyarakat agricultural traditional. Metode penelitian yang digunakan adalah pretest-posttest design dengan tehnik consecutive sampling dan jumlah sampel sebesar 40 org di bagi menjadi 4 kelompok, masing-masing kelompok diberikan perlakuan sebanyak 4x dalam 2 minggu. Alat ukur yang digunakan adalah kuesioner dan skala ISI kemudian dianalisis dengan paired sample t-test. Berdasarkan hasil penelitian menunjukkan terdapat efektifitas tehnik acuyoga terhadap insomnia pada ibu hamil dengan $\mathrm{t}_{\text {hitung }}=13.397$ dengan $\mathrm{t}_{\text {tabel }}=0.021$. diharapkan tehnik acuyoga dapat
\end{abstract}


menjadi salah satu tehnik untuk mengurangi insomnia pada ibu hamil karena tehnik ini dapat merelaksasi otot-otot tubuh sehingga ibu hamil terasa nyaman.

Kata Kunci: acuyoga, insomnia, ibu hamil trimester 3

Perubahan anatomi dan fisiologi pada perempuan hamil sebagian besar sudah terjadi segera setelah fertilisasi dan terus berlanjut selama kehamilan, kebanyakan perubahan ini merupakan respons terhadap janin. Perubahan anatomi fisiologi ini memberikan masalah pada ibu hamil terutama gangguan tidur (Insomnia). Gangguan tidur yang sering dialami oleh ibu hamil adalah penurunan durasi tidur (Field et al., 2007). Sebagian besar wanita hamil mengalami gangguan tidur dan hanya 1,9\% saja wanita yang tidak terbangun pada malam hari selama kehamilan trimester ketiga. Gangguan tidur pada wanita hamil bisa berupa penurunan presentase gelombang tidur yang lamban dan tidur REM yang mungkin meningkat pada stadium satu. Gangguan tidur pada wanita hamil terjadi pada trimester pertama, trimester kedua dan juga trimester ketiga. Gangguan tidur lebih banyak dikeluhkan pada trimester ketiga (Field et al, 2006). Pada trimester tiga jumlah gangguan tidur ini lebih tinggi, karena adanya ketidaknyamanan seperti nyeri pinggang hal ini disebabkan karena kompensasi dari pembesaran uterus ke posisi anterior, lordosis menggeser pusat daya berat ke belakang kearah dua tungkai. Sendi Sakroiliaka, sakrokoksigis dan pubis akan meningkat mobilitasnya, yang diperkirakan karena pengaruh hormonal, hal ini menyebabkan perasaan tidak enak pada bagian bawah punggung terutama pada akhir kehamilan. (Prawirohardjo, 2008) banyak buang air kecil, dan spontan bangun dari tidur. Gerakan janin, nyeri ulu hati (hurtburn), kram pada tungkai, kelelahan dan kesulitan memulai tidur atau sulit tidur sampai pagi (Grace et al, 2004). Penurunan durasi tidur pada ibu hamil dapat membuat kondisi ibu hamil menurun, konsentrasi berkurang, mudah lelah, badan terasa pegal, tidak mood bekerja, dan cenderung emosional. Hal ini dapat membuat beban kehamilan menjadi semakin berat (Bambang BR, 2004). Gangguan tidur menimbulkan depresi dan stres yang berpengaruh pada janin yang dikandungnya. Stres ringan menyebabkan janin mengalami peningkatan denyut jantung, tetapi stres yang berat dan lama akan membuat janin menjadi hiperaktif. Akibat lanjut dari gangguan tidur ini adalah depresi dan bayi yang dilahirkan memiliki sedikit waktu tidur yang dalam (Field et al, 2007). Kesulitan tidur pada ibu hamil disebabkan oleh adanya rasa cemas dan panik yang berkaitan dengan perubahan tanggung jawab sebagai orang tua.Gangguan tidur selama kehamilan terjadi selama trimester $1(13 \%$ $80 \%$ ) dan trimester ketiga (66\%-97\%). Upaya-upaya untuk mengatasi kesulitan tidur ini antara lain dengan olah raga, mengkonsumsi obat-obatan yang aman bagi ibu hamil, hipnoterapi, edukasi tidur (sleeping education) dan latihan relaksasi (Hegard, Hanke K, 2010).

Salah satu latihan relaksasi yaitu dengan cara acuyoga. Acuyoga dapat meredakan keluhan insomnia yang disebabkan karena nyeri punggung, stress dll.Acuyoga terdiri dari latihan pernafasan, meditasi, relaksasi dan menggunakan titik meridian dalam tubuh untuk mengatasi stress dan nyeri punggung yang bisa menyebabkan insomnia pada ibu hamil. Penerapan acuyoga diterapkan dalam masyarakat tradisional dimana kebanyakan mata pencaharian masyarakatnya adalah petani, dan masih menganut adat istiadat yang kuat yang ada di dalam lingkungannya. Kehidupan disana masih statis,belum terpengaruh oleh perubahan-perubahan yang ada. Acuyoga dalam masyarakat tersebut, masih awam tetapi mereka sedikit mengenal tentang pemijatan tradisional.

Menurut penelitian Mediarti (2014), menunjukan hasil uji statistik $p=0,0005$, dimana terdapat perbedaan yang sangat signifikan pada keluhan ibu hamil sebelum dilakukan yoga antenatal dan setelah dilakukan yoga antenatal. Pada penelitian wahyuni dan Layinatun Ni'mah (2013) disebutkan bahwa Hasil penelitian menunjukkan bahwa senam hamil berpengaruh dalam peningkatan durasi tidur ibu hamil pada trimester ketiga, ditunjukkan dengan nilai $p=$ $0,004(p<0,005)$. Hal ini disebabkan karena senam hamil akan memberikan efek relaksasi pada ibu hamil yang bisa berpengaruh terhadap peningkatan durasi tidur bagi ibu hamil.

Berdasarkan latar belakang diatas dapat dirumuskan permasalahan, bagaimanakah efektifitas acuyoga terhadap keluhan insomnia pada ibu hamil trimester III di masyarakat Agriculture Traditional kecamatan Ngancar Kabupaten Kediri? Masyarakat dengan traditional agrikultur mempunyai suatu budaya yang unik dalam hal kesehatan. Mereka selalu menggunakan ramuan-ramuan herbal untuk meng- 
atasi masalah kesehatan khususnya insomnia. Oleh karena itu peneliti menginginkan penelitian di masyarakat tersebut, selain mengenalkan teknik acuyoga juga dapat memeberikan mereka masukan untuk hidup sehat dan bahagia selama kehamilan.

\section{BAHAN DAN METODE}

Jenis penelitian adalah pre test-post test design. Sampel diambil dengan tehnik consecutive sampling dengan 40 responden yang terbagi menjadi 4 kelompok masing-masing kelompok sebanyak 10 responden yang diberikan perlakuan selama $4 x$ dalam 2 minggu.

Variabel dependen adalah teknik acuyoga dan variabel independen adalah penurunan insomnia pada ibuhamil trimester 3. Alat ukur yang digunakan adalah kuesioner untuk data umum antara lain usia, pekerjaan, pendidikan responden. Untuk mengukur insomnia pada ibu hamil trimester 3 menggunakan skala ISI (Insomnia Severity Index).

Analisis data menggunakan uji statistik paired sample t-test dengan signifikasi 0,05 .

\section{HASIL PENELITIAN}

\section{Data Umum}

Tabel 1 Distribusi frekuensi karakteristik responden di Wilayah Kerja Puskesmas Ngancar Kabupaten Kediri tahun $2017(n=40)$

\begin{tabular}{lllc}
\hline No & Kriteria & $\begin{array}{l}\text { Karakteristik } \\
\text { responden }\end{array}$ & f \\
\hline 1 & Usia & $20-23$ & 14 \\
& & $24-26$ & 11 \\
& & $27-29$ & 11 \\
2 & \multirow{4}{*}{ Pendidikan } & $30-32$ & 4 \\
& & SD & 6 \\
& & SMP & 10 \\
& & SMA & 18 \\
3 & Pekerjaan & PT & 6 \\
& & IRT & 18 \\
& & Buruh Tani & 8 \\
& & Swasta & 8 \\
4 & Riwayat Keha- & PNS & 4 \\
& milan & Primi & \\
\hline
\end{tabular}

Berdasarkan Tabel 1 menunjukkan bahwa usia responden sebagian besar berusia 20-23 tahun. Jenjang pendidikan responden sebanyak 18 responden berpendidikan SMA. Serta sebagian besar adalah Ibu Rumah Tangga (IRT) sebanyak 18 responden. Riwayat kehamilan semuanya merupakan primi gravida.

\section{Data Khusus}

Tabel 2 Distribusi frekuensi kategori insomnia sebelum dilakukan intervensi di wilayah Kerja Puskesmas Ngancar Kabupaten Kediri tahun $2017(n=40)$

\begin{tabular}{llc}
\hline No & Kategori Insomnia & f \\
\hline 1 & Tidak ada insomnia yang signifikan & \\
& secara klinis & 14 \\
2 & Subthreshold insomnia & 24 \\
3 & Insomnia Klinis (Keparahan Sedang) & 2 \\
4 & Insomnia Klinis (parah) & 0 \\
\hline
\end{tabular}

Berdasarkan Tabel 2 diatas menunjukkan bahwa sebagian besar responden mengalami Subthreshold insomnia sebesar 24 responden.

Tabel 3 Distribusi frekuensi kategori insomnia sesudah dilakukan intervensi di Wilayah Kerja Puskesmas Ngancar Kabupaten Kediri tahun $2017(n=40)$

\begin{tabular}{llc}
\hline No & Kategori Insomnia & f \\
\hline 1 & Tidak ada insomnia yang signifikan & \\
& secara klinis & 36 \\
2 & Subthreshold insomnia & 4 \\
3 & Insomnia Klinis (Keparahan Sedang) & 0 \\
4 & Insomnia Klinis (parah) & 0 \\
\hline
\end{tabular}

Berdasarkan Tabel 3 diatas menunjukkan bahwa sebagian besar responden tidak ada insomnia yang signifikan secara klinis sebesar 36 responden.

Tabel 4 Nilai numerik deskriptif dan uji paired t-test dari responden sebelum intervensi dan sesudah intervensi

\begin{tabular}{lccccc}
\hline & N & Rata-rata & Simpangan baku & Rata-rata \pm simpangan baku & p \\
\hline Sebelum intervensi & 40 & 9,4000 & 3,521 & \multirow{2}{*}{$6,125 \pm 2,747$} & $<0,001$ \\
Sesudah intervensi & 40 & 3,2750 & 1,894 & & \\
\hline
\end{tabular}


Berdasarkan Tabel 4 diatas menunjukkan bahwa terjadi kenaikan rata-rata pada sebelum dan sesudah intervensi sebesar 6.125 poin. hasil uji Paired sample t-test didapatkan nilai $\rho<\alpha$ berarti terdapat perbedaan yang signifikan insomnia responden sebelum intervensi dan sesudah intervensi.

\section{PEMBAHASAN}

\section{Sebelum Dilakukan Intervensi Acuyoga}

Wanita hamil trimester 3 akan mengalami peubahan baik fisiologis maupun psikologis. Perubahan fisiologis antara lain sakit pinggang akibat karena meningkatnya berat badan bayi dalam kandungan, keluarnya colostrum pada payudara, konstipasi karena rahim yang membesar kedaerah usus selain peningkatan hormon progesteron, susah bernafas diakibatkan oleh tekanan bayi yang berada dibawah diagfragma yang menekan paru ibu, sering BAK karena kepala bayi yang turun ke rongga panggul akan menekan kandung kemih, insomnia yang diakibatkan karena gerakan janin pada malam hari (Dewi et al, 2011)

Berdasarkan hasil penelitian sebelum dilakukan intervensi berupa acuyoga menunjukkan bahwa sebagian besar responden mengalami insomnia pada level subthreshold insomnia, dan hanya 2 responden yang mengalami insomnia klinis (keparahan sedang). Hal ini di karenakan oleh tingkat pendidikan responden, dimana responden yang berpendidikan tinggi cenderung terkena insomnia, baik dari gerakan janin bahkan karena tingkat kecemasan saat persalinan. Selain itu, posisi tidur tidak nyaman dan insomnia yang dirasakan ibu hamil trimester III disebabkan oleh tekanan darah dalam tubuh meningkat dan jantung memompakan darah dengan cepat. Seiring dengan perut yang semakin membesar, gerakan janin dalam uterus dan rasa tidak enak di ulu hati (Bobak, 2005).

Menurut Varney (2002) menyebutkan, ibu hamil yang berolah raga secara teratur, tingkat laporan mengalami ketidaknyamanan selama proses kehamilan lebih rendah, dan penyembuhan lebih cepat dibandingkan dengan yang tidak berolahraga selama kehamilan. Bagi yang giat berolahraga, membutuhan sedikit intervensi Sectio Caesarea (SC) dan dapat memperpendek kala I dan II persalinan dibandingkan dengan yang tidak berolah raga.

Usia juga dapat mempengaruhi kualitas tidur ibu hamil, hal ini dikarenakan usia muda mempunyai stamina yang lebih bagus dari pada hamil pada usia resiko tinggi (Karger,2009). Selain itu, demografi lokasi penelitian pegunungan berapi yang masih aktiv serta pada tahun 2014 terjadi erupsi gunung berapi terbesar yang menyebabkan kerusakan dalam radius $10 \mathrm{Km}$, sehingga berdampak pada ekonomi masyarakat berupa kerusakan pada rumah dan lahan pertanian serta kesehatan. Oleh karena itu, masyarakat wilayah kerja PKM ngancar saat penelitian berlangsung sedang menaikkan ekonomi keluarga, hal ini berdampak pada beberapa ibu hamil sehingga mengalami insomnia karena memikirkan kandungan serta ekonomi keluarga ditambahkan lagi rasa percaya diri dan keyakinan terhadap diri sendiri dan kehamilannya masih kurang, hal ini terlihat saat proses penelitian berlangsung banyak dari responden yang kurang tahu tentang kehamilan dan pentingnya olahraga dalam menjaga kehamilan khususnya pada trimester 3 .

\section{Sesudah Dilakukan Intervensi Acuyoga}

Kebutuhan fisiologis dasar manusia terdiri atas hygiene, nutrisi, tidur, kenyamanan, oksigenasi, dan eliminasi (Potter \& Perry, 2006). Kebutuhan dasar yang paling mudah terpenuhi adalah kebutuhan akan tidur, istirahat dan tidur sama pentingnya dengan kebutuhan dasar lain. Tidur merupakan hal yang esensial bagi kesehatan (Perni, 2009). Manfaat tidur akan terasa ketika seseorang mencapai tidur yang berkualitas. Kualitas tidur seseorang akan menghasilkan kesegaran dan kebugaran disaat terbangun. Tidur yang tidak adekuat danberkualitas buruk dapat menyebabkan gangguan keseimbangan fisiologis danpsikologis. Agar ibu hamil trimester 3 beradaptasi dengan beberapa perubahan, maka salah satunya dengan terapi acuyoga.

Menurut hasil penelitian setelah dilakukan terapi acuyoga selama 4 kali dalam 2 minggu didapatkan bahwa hampir semuanya pada level tidak ada insomnia yang signifikan secara klinis. Hal ini dikarenakan karena ibu hamil yang melakukan terapi acuyoga membantu ibu lebih rileks sehingga kualitas tidur terpenuhi.

Acuyogakombinasi dari acupresure dan yoga. Dimana, pada penelitian ini melakukan acupresure yang merupakan pijatan pijatan yang halus di titiktitik non merdian yang berfungsu untuk menormalkan mekanisme dan respon homeostatik dan mekanisme ditubuh responden. Teoristres Selye dalam Atika (2013), menjelaskan efektifitas fisiologi dari massage merupakan respon terpadu yang berasal dari hipotalamus yang mengarah kenaikan atau 
penurunan gairah dari sistem saraf pusat. Back Massage dapat memproduksi endomorfin dengan mengurangi ketegangan otot adalah kebalikan dari respon stres. Hal ini diperkuat dengan penelitian oleh Atika (2013), bahwa Pemberian interverensi back massage dalam peningkatan kualitas tidur pada ibu hamil trimester tiga di Puskesmas Batang II di dapatkan hasil bahwa terdapat pengaruh Back Massage terhadap kualitas tidur pada ibu hamil trimester tiga dimana dalam pelaksanaannya menggunakan pengukuran dengan kuisioner the Pittsburgh sleep Quality index (PSQI).

Sedangkan yoga dalam penelitian ini menggunakan gerakan surya namaskar dimana, gerakan ini dilakukan secara perlahan dan teratur, pernafasan yang teratur serta meditasi yang diiringi musik klasik, sehingga dapat membuat responden menjadi rileks bahkan tertidur saat meditasi.

Dr. Vivek Narendran dari Ciccinnati Children's Hospitality Medical Center di Ohio Amerika Serikat mengatakan latihan yoga dapat membantu memperlancar aliran darah ke plasenta, menurunkan transfer hormon stres ibu ke tubuh janin, menurunkan pelepasan hormon yang memicu terjadinya kelahiran sehingga memperkecil kemungkinan kelahiran prematur. Selain itu, yoga juga dapat menurunkan tingkat kecemasan ibu hamil trimester 3. Menurut penelitian dari Hariyanto (2015), terdapat pengaruh senam yoga terhadap tingkat kecemasan ibu hamil trimester III di praktik Bidan Mandiri Kabupaten Boyolali pada kelompok perlakuan.

Di perkuat juga oleh penelitian Wagey (2011), menunjukkan bahwa perlakuan senam hamil pada wanita hamil yang usia kehamilannya memasuki umur 20 minggu memberikan peningkatan antioksidan enzimatik SOD, GSHPx, dan CAT dan penurunan MDA dan 8-OHdG lebih tinggi dibandingkan dengan kelompok yang tidak mendapatkan senam hamil.

\section{Efektivitas Acuyoga Terhadap Insomnia Pada Ibu Hamil Trimester 3}

Hormon yang meningkat selama kehamilan adalah hormon adrenalin.Hormon adrenalin dapat menimbulkan disregulasi biokimia tubuh sehingga muncul ketegangan fisik pada ibu hamil seperti mudah marah, gelisah, tidak mampu memusatkan pikiran, ragu-ragu bahkan mungkin ingin lari dari kenyataan hidup (Dariyo, 1997 dalam Wulandari, 2006). Menurut Pieter dan Lubis, (2010) ibu hamil akan mengalami bentuk-bentuk perubahan psikis yaitu perubahan emosional, cenderung malas, sensitif, gampang cemburu, minta perhatian lebih, perasaan tidak nyaman, depresi, stress dan cemas dan insomnia, begitu juga menurut Maya (2008) bahwa penurunan jumlah tidur (terjadi karena ibu susah untuk tidur (insomnia), hal ini dirasakan sebagai akibat dari meningkatnya kecemasan atau kekhawatiran dan ketidaknyamanan fisik.

Menurut hasil penelitian yang dilakukan dalam 4 kali pertemuan selama 2 minggu menunjukkan bahwa, terdapat perbedaan yang signifikan penurunan insomnia responden sebelum intervensi dan sesudah intervensi.

Acupresure pada penelitian ini setelah melakukan yoga dan meditasi. Pijatan-pijatan pada titiktitik Pai Hui, Yin Tang, Ting Kung, Tay Yang, Teu Wei, I Fung, I Fung Ce. Masing-masing titik ini dilakukan penekanan, pengetukan dan pijatan yang lembut selama 1-5 menit, sehingga dapat memberikan efek relaksasi yaitu dapat mengurang keluhan seperti sakit kepala, vertigo, migrain, meningkatkan konsentrasi, mengatur nafsu makan dan minum, melancarkan peredaran darah (Wong,2011).

Menurut Penelitian dari Richard (2000), menunjukkan bahwa massage dapat membantu menyelesaikan permasalahan seperti kecemasan, depresi, stres, nyeri dan insomnia dengan mengurangi ketegangan otot. Di perkuat juga oleh penelitian yang dilakukan oleh Hollenbach, Broker, Herley, dan Stuber (2013) mengatakan bahwa dari intervensi non farmakologi terapi masase dapat meningkatkan kualitas tidur pada ibu hamil. Menurut penelitian Adams (2010) tentang managemen nyeri menjelaskan terapi masase dapat mengurangi nyeri, menurunkan emosional, relaksasi, dan kemampuan untuk tidur.

Yoga dengan gerakan suryanamaskar yang terdiri dari 12 gerakan, dimana 12 gerakan ini merupakan gerakan yang dinamis dan berenergi dengan pernapasan yang teratur setiap gerakan selama 1-2 menit dan diakhiri dengan meditasi sehingga dapat membantu menenangkan pikiran.Berdasarkan beberapa penelitian, dinyatakan bahwa yoga dapat membantu memberikan ketenangan jiwa dan pikiran karena dapat dijadikan sebagai salah satu coping stress (Bribiscas, 2013; Williams-Orlando, 2013; Khalsa, Butzer, Shorter, Reinhardt, \& Cope, 2013; Bala, 2012) dan meningkatkan self-efficacy (WilliamOrlando, 2013; Khalsa, Butzer, Shorter, Reinhardt, $\&$ Cope, 2013).

Yoga juga memberikan beberapa mafaat seperti meredakan nyeri pada beberapa anggota tubuh, mengatur ritme nafas untuk mencapai kondisi relaks, 
mengatur ritme jantung, serta memperbaiki kualitas tidur (Bala, 2012). Oleh karena itu, terapi acupresure dan yoga sangat diperlukan bagi ibu hamil trimester 3 selain untuk meningkatkan stamina juga sebagai salah satu cara untuk mengurangi insomnia. Gerakan yoga yang lembut, pernafasan dan pemijatan yang perlahan akan memberikan rasa nyaman pada ibu hamil trimester 3 .

\section{SIMPULAN DAN SARAN}

\section{Simpulan}

Berdasarkan hasil penelitian diatas didadaptkan bahwa pelaksanaan terapy acuyoga berjalan dengan lancar dan baik.

Hasil evaluasi sebelum dilakukan acuyoga menunjukkan bahwa sebagian besar responden mengalami Subthreshold insomnia sebesar 24 responden. Sesudah di lakukan acuyoga sebagian besar responden tidak ada insomnia yang signifikan secara klinis sebesar 36 responden. Hasil uji Paired sample t-test didapatkan nilai $\rho<\alpha$ berarti terdapat perbedaan yang signifikan insomnia responden sebelum intervensi dan sesudah intervensi.

\section{Saran}

Terapi acuyoga perlu dilalukan 2 kali selama 1 minggu saat ibu hamil memasuki trimester 3 , dan diharapkan ibu hamil serta petugas kesehatan dapat memotivasi agar ibu hamil melakukan acuyoga untuk kelancaran dan kesehatan pada saat persalinan.

Ibu hamil yang melakukan terapi acuyoga diperlukan kesungguhan dan serta rasa tertarik agar lebih dapat mendapatkan manfaat secara fisiologis dan psikologis serta instruktur memberikan informasi secara konsisten untuk menunjang rasa percaya diri dan rasa yakin pada ibu hamil, khususnya primigravida.

\section{DAFTAR RUJUKAN}

Adams, W. K \& Wieman, C. E. 2010. Development and Validation of Instruments to Measure Learning of Expert-Like Thinking. International Journal of Science Education, 33 (9), 1-24

Astuti, Maya. 2010. Buku Pintar Kehamilan.Jakarta : EGC: 16.

Atika, Anna Fita. 2013. Pengaruh Back Massage Terhadap Ibu Hamil Trimester Tiga.Program Studi Diploma IV Fisioterapi. Fakultas Ilmu Kesehatan. Universitas Muhammadiyah Surakarta.

Bala, K. 2012. Pregnancy \& Yoga.Retrieved 2017, from www.midwiferytoday.com.

Bobak, I.M., Lowdermilk, D. \& Jensen, M.D. 2005. Kepe- rawatan maternitas. Alih bahasa. Wijayarini, M.A. \& Anugerah, P.I. Edisi 4. Jakarta: EGC.

Bribiescas, S. 2013. Yoga in Pregnancy. International Journal of Childbirth Education, 99-102.

Dewi, Vivian Nanny Lia; Sunarsih, Tri. 2011. Asuhan Kebidanan Ibu Nifas. Jakarta : Salemba Medika

Field et al. 2006. Sleep Disturbansces in Depressed Pregnant Women and Their Newborns. Infant Behavior and Development.

Grace, Pierce A \& Borley Neil R. 2006. At a Glance Ilmu Bedah. Surabaya: Erlangga.

Hariyanto. 2015. Pengaruh Senam Yoga Terhadap Tingkat kecemasan Ibu Hamil Trimester III di Praktek Bidan Mandiri Kabupaten Boyolali. Program Studi S1 Fisioterapi. Fakultas Ilmu Kesehatan. Universitas Muhamadiyah Surakarta.

Hegard, Hanne dan Hanke. 2010. Experience of Physical Activity During Pregnancyin Danish Nulliparous Women with A Physically Active Life Before Pregnancy, A Qualitative Study. BMC Pregnancy and Childbirth.

Helen Varney. 2002. Buku Saku Bidan. Jakarta

Khalsa, S. B., Butzer, B., Shorter, S., Reinhardt, K., \& Cope, S. 2013 (Mar/Apr). Yoga reduces performance anxiety in adolescent musicians. Alternative Therapies, 19, 34-44.

Karger, S.A.G. 2009. Sleep and Vigilance Disorders in Pregnancy. Di akses tanggal 1 Agustus 2017 dari http://content.karger.com

Mediarti, Devi, Sulaiman, Rosnani, Jawiah. 2014. Pengaruh Yoga Antenatal Terhadap Pengurangan Keluhan Ibu Hamil Trimester III. Jurnal Kedikteran, Vol 1, Oktober 2014: 47-53. Politeknik Kesehatan Kemenkes RI Palembang Jurusan Keperawatan.

Pieter, H.Z. \& Lubis, N.L. 2010. Pengantar Psikologi Dalam Keperawatan.Kencana. Jakarta.

Stewart, D.E., Robertson, E., Dennis, L.C., Grace, S.L., Wallington, T. 2003. Postpartum Depression: Literature Review Of Risk factors and Interventions. University Health Network Womens Health program.

Wagey. 2011. Senam Hamil Meningkatkan Antioksidan Enzimatik, Kekuatan Otot Panggul, Kualitas Jasmani dan Menurunkan Kerusakan Oksidatif Pada wanita Hamil. Program Pasca Sarjana Universitas Udayana Denpasar.

Wahyuni dan Ni'mah, Layinatun. 2013. Manfaat Senam Hamil Untuk Meningkatkan Durasi Tidur Ibu Hamil. Surakarta: Universitas Muhammadiyah Surakarta.

Wulandari, Primatia Yogi. 2006. Efektivitas Senam Hamil sebagai Pelayanan Prenatal dalam menurunkan Kecemasan Menghadapi Persalinan Pertama. INSAN. Vol. 8 No. 2

Wong, Ferry. 2011. Acuyoga Kombinasi Akupresure dan Yoga. Penebar Plus. Jakarta. 